\title{
Geographic variation in the provider of screening colonoscopy in Canada: a population-based cohort study
}

\author{
Aristithes G. Doumouras MD MPH, Sama Anvari BHSc, Margherita Cadeddu MD, \\ Mehran Anvari MD PhD, Dennis Hong MD MSc
}

\section{Abstract}

Background: Screening colonoscopy for the detection of colorectal carcinoma is provided by several specialties. Few studies have assessed geographic variation in the delivery of this care. Our objective was to investigate how geographic and socioeconomic factors affect who provides screening colonoscopy in Canada.

\begin{abstract}
Methods: This was a population-based cohort of all screening colonoscopy procedures performed at publicly funded Canadian health care facilities (excluding those in Quebec) between April 2008 and March 2015. The main outcome of interest was the proportion of colonoscopy procedures performed by surgeons versus gastroenterologists at the neighbourhood level. Predictors of interest included socioeconomic and geographic variables. We used spatial analysis to evaluate significant clustering of practitioner services and multinomial logistic regression to model predictors.

Results: We identified 658113 screening colonoscopy procedures performed by 1886 providers (1169 surgeons and 717 gastroenterologists) over the study period, of which 353165 (53.7\%) were performed by surgeons. A total of $24.2 \%$ of neighbourhoods were located within clusters predominantly served by gastroenterologists, and $19.5 \%$ were within surgeon clusters; the remainder were in mixed clusters. Rural neighbourhoods had a significantly increased relative risk of being within a surgeon cluster (relative risk [RR] $5.38,95 \%$ confidence interval [Cl] 3.48-8.01) compared to mixed clusters and nearly 100 times higher relative risk of being in a surgeon cluster compared to gastroenterologist clusters (RR 98.95, 95\% Cl 15.3-427.2). Neighbourhoods with the highest socioeconomic status were $1.74(95 \% \mathrm{Cl} 1.14-2.56)$ times likelier to be in gastroenterologist clusters than in mixed clusters.
\end{abstract}

Interpretation: Surgeons provide a large proportion of colonoscopy procedures in Canada and are essential for access to care, particularly in rural regions. Most Canadians are served relatively equally by surgeons and gastroenterologists. This emphasizes the importance of both specialties to the delivery of colonoscopy care across the country.

olorectal cancer is the third most commonly diagnosed and fourth most common cause of cancerrelated death in men and women, respectively, worldwide. ${ }^{1}$ In 2012, 1.4 million people received a diagnosis of colorectal cancer, and it was estimated that 700000 of these people would die from the disease. ${ }^{1}$ High disease incidence and mortality have led to the development of multiple screening modalities, many of which detect and remove colonic polyps that are precursors to many colorectal cancers. ${ }^{2}$ Of these, colonoscopy is most sensitive test for detecting colorectal cancer and adenomas. ${ }^{3}$ As a common primary screening test, colonoscopy has been shown to decrease the incidence of colorectal cancer and associated mortality, 4,5 and a recent meta-analysis suggested that it is a more effective screening tool than guaiac-based fecal occult blood testing or flexible sigmoidoscopy. ${ }^{6}$

There is conflicting evidence as to whether endoscopist specialty affects patient outcomes. Some studies have shown that, compared to patients treated by general surgeons or other specialists, patients who underwent colonoscopy performed by a gastroenterologist were significantly more likely to have polyps detected $d^{7-9}$ and removed ${ }^{10}$ and had lower rates of bowel perforation, ${ }^{11}$ and colorectal cancer was less likely to develop in these patients. ${ }^{12}$ However, other studies have revealed no significant difference in polyp detection ${ }^{13}$ or complication rates ${ }^{14}$ between gastroenterologists and surgeons, with at least 1 study showing that gastroenterologists have significantly higher total complication rates than surgeons. ${ }^{13}$ Despite these findings, little

\section{Competing interests: None declared.}

This article has been peer reviewed.

Correspondence to: Dennis Hong, dennishong70@gmail.com

CMAJ Open 2018. DOI:10.9778/cmajo.20170131 
is known as to whether the populations these specialists serve are the same and how important either specialty is to the delivery of colonoscopy care, as provider delivery in urban and rural areas has been found to vary. ${ }^{15}$ In addition, residents of rural areas have been shown to have lower screening rates than urban residents ${ }^{16-18}$ and a higher proportion of their colonoscopy procedures done by general surgeons. ${ }^{15}$ Furthermore, the nature of the 2 professions differs and allows for varied roles in the delivery of endoscopy. Gastroenterologists can be more focused and may have a high-volume endoscopy practice, but their specialty may not be as suitable to rural areas. Few researchers have investigated geographic variations in the delivery of colonoscopy and what factors affect that variation. This information is vital to understanding and planning the delivery of colonoscopy care as well as contextualizing differences in outcomes. As such, the purpose of this study was to investigate variations in the delivery of screening colonoscopy by specialty across Canada.

\section{Methods}

\section{Design and setting}

This was a retrospective cohort study of all adult (age $\geq 18 \mathrm{yr}$ ) patients who underwent screening colonoscopy in a publicly funded facility between April 2008 and March 2015 in Canada (excluding Quebec). Screening colonoscopy guidelines are relatively similar across Canadian provinces, and major evidence for colorectal screening did not change during the study period, as the Canadian Task Force on Preventive Health Care updated their guidelines in 2016 from the 2001 guidelines. ${ }^{3,19}$

\section{Data sources and definitions}

We defined screening colonoscopy as a procedure aiming to detect and remove polyps and/or early-stage lesions. ${ }^{19} \mathrm{We}$ derived patient, procedure, provider, distance and neighbourhood data from the Canadian Institute for Health Information Discharge Abstract Database and National Ambulatory Care Reporting System. We excluded Quebec as its data are not accessible directly from the Canadian Institute for Health Information but only through the Quebec Ministry of Health and Social Services. We identified screening colonoscopy by a colonoscopy procedure clarified by a screening diagnosis code. Both databases have been previously validated, and both showed high sensitivity for procedures. ${ }^{20-22}$ Other administrative databases have been validated for colonoscopy, with a $99 \%$ correlation with the correct procedure and a specificity of $76 \%$ in 1 study and over $95 \%$ in another study for the correct indication..$^{23,24} \mathrm{We}$ defined neighbourhoods as forward sortation areas, which are a unit of area used by the Canadian postal system denoted by the first 3 digits of the postal code. We derived geographic data for the forward sortation areas from the 2013 Canadian census files ${ }^{25}$ and obtained neighbourhood income data from Statistics Canada. Rurality was defined through the postal code. ${ }^{26,27}$ The median individual income for each neighbourhood was the specific income measure used and was derived from Statistics Canada data. ${ }^{27}$

\section{Outcome measures and regression variables}

The main outcome of interest in this study was the neighbourhood ratio of screening colonoscopy procedures done by surgeons versus gastroenterologists/internists. Colonoscopy procedures done by other providers accounted for less than $2 \%$ of all procedures and were excluded. The main geographic and socioeconomic factors of interest were distance to the colonoscopy facility, neighbourhood rurality and neighbourhood socioeconomic status.

\section{Statistical analysis}

We calculated the main outcome as the proportion of total colonoscopy procedures within a neighbourhood done by surgeons. To determine the spatial relation between neighbourhoods and specialty, we performed a geographic cluster analysis using the Getis-Ord Gi* statistic. This statistic determines whether the neighbourhood and all of its adjacent neighbours are significantly different from the overall mean. For this analysis, we defined neighbourhood connectivity as having an adjacent border. Neighbourhood clusters were then classified as a surgeon cluster, a gastroenterologist cluster high use or a mixed cluster. We carried out spatial analyses using the ArcGIS Desktop suite (ArcMap10.1, Environmental Systems Research Institute). We compared univariable comparisons of geographic and socioeconomic factors across surgical rate groups and clusters using analysis of variance or a $\chi^{2}$ test, as appropriate. To determine the effect of the neighbourhood and socioeconomic factors on neighbourhood cluster status, we used a multilevel multinomial logistic regression with the geographic and socioeconomic factors as fixed effects and the provinces as random effects. Importantly, this methodology allows for an unbiased evaluation of the effects by accounting for differences in use between provinces. Results are presented as surgeon and gastroenterologist neighbourhoods compared to mixed neighbourhoods, as well as surgeon neighbourhoods compared directly to gastroenterologist neighbourhoods. Owing to the use of multinomial regression, we report relative risk (RR) with $95 \%$ confidence intervals (CIs). Statistical significance was set at $p<0.05$. We used Stata statistical software release 12.1 (StataCorp) and MLwiN version 2.26 (Centre for Multilevel Modelling, University of Bristol) for data analysis.

\section{Ethics approval}

This study was approved by the Hamilton Integrated Research Ethics Board.

\section{Results}

A total of 658113 screening colonoscopy procedures were performed over the study period, 353165 (53.7\%) by surgeons $(n=1169)$ and $304948(46.3 \%)$ by gastroenterologists $(n=717)$. Surgeons performed 100195 colonoscopy procedures $(28.4 \%$ of their total colonoscopy procedures) in rural areas, compared to 37893 procedures (12.4\%) for gastroenterologists $(p<0.001)$ (Table 1$)$. A third $(32.9 \%)$ of procedures done by gastroenterologists were done in neighbourhoods with the highest socioeconomic status, compared to 
Research

$17.7 \%$ for surgeons $(p<0.001)$. Patients of surgeons travelled farther than patients of gastroenterologists (mean $27.0 \mathrm{~km} \mathrm{v}$. $21.3 \mathrm{~km}, p<0.001)$.
Figure 1 and Table 2 present the results of the cluster analysis. Of the 1114 neighbourhoods analyzed, $270(24.2 \%)$ were within a cluster that had significantly higher rates of

\begin{tabular}{|lccc|}
\hline \multicolumn{2}{|l|}{ Table 1: Association between colonoscopy provider and regression covariates } \\
\hline Variable & $\begin{array}{c}\text { Gastroenterologists } \\
n=717\end{array}$ & $\begin{array}{c}\text { Surgeons } \\
n=1169\end{array}$ & $p$ value \\
\hline Annual volume, mean \pm SD & $79.4 \pm 99.8$ & $54.5 \pm 77.9$ & \\
\hline $\begin{array}{l}\text { Total no. (\%) of colonoscopy } \\
\text { procedures }\end{array}$ & $304948(46.3)$ & $353165(53.7)$ & \\
\hline $\begin{array}{l}\text { No. }(\%) \text { of procedures in rural } \\
\text { areas }\end{array}$ & $37893(12.4)$ & $100195(28.4)$ & $<0.001$ \\
\hline $\begin{array}{l}\text { Socioeconomic quartile; } \\
\text { no (\%) of procedures }\end{array}$ & $50010(16.4)$ & $64145(18.2)$ & $<0.001$ \\
\hline 1 & $73181(24.0)$ & $129133(36.6)$ & \\
\hline 2 & $81330(26.7)$ & $97383(27.6)$ & \\
\hline 3 & $100427(32.9)$ & $62504(17.7)$ & \\
\hline 4 & $21.3 \pm 52.6$ & $27.0 \pm 65.5$ & \\
\hline $\begin{array}{l}\text { Distance to hospital, mean } \\
\pm \text { SD; km }\end{array}$ & & & \\
\hline Note: SD = standard deviation. & & & \\
\hline
\end{tabular}

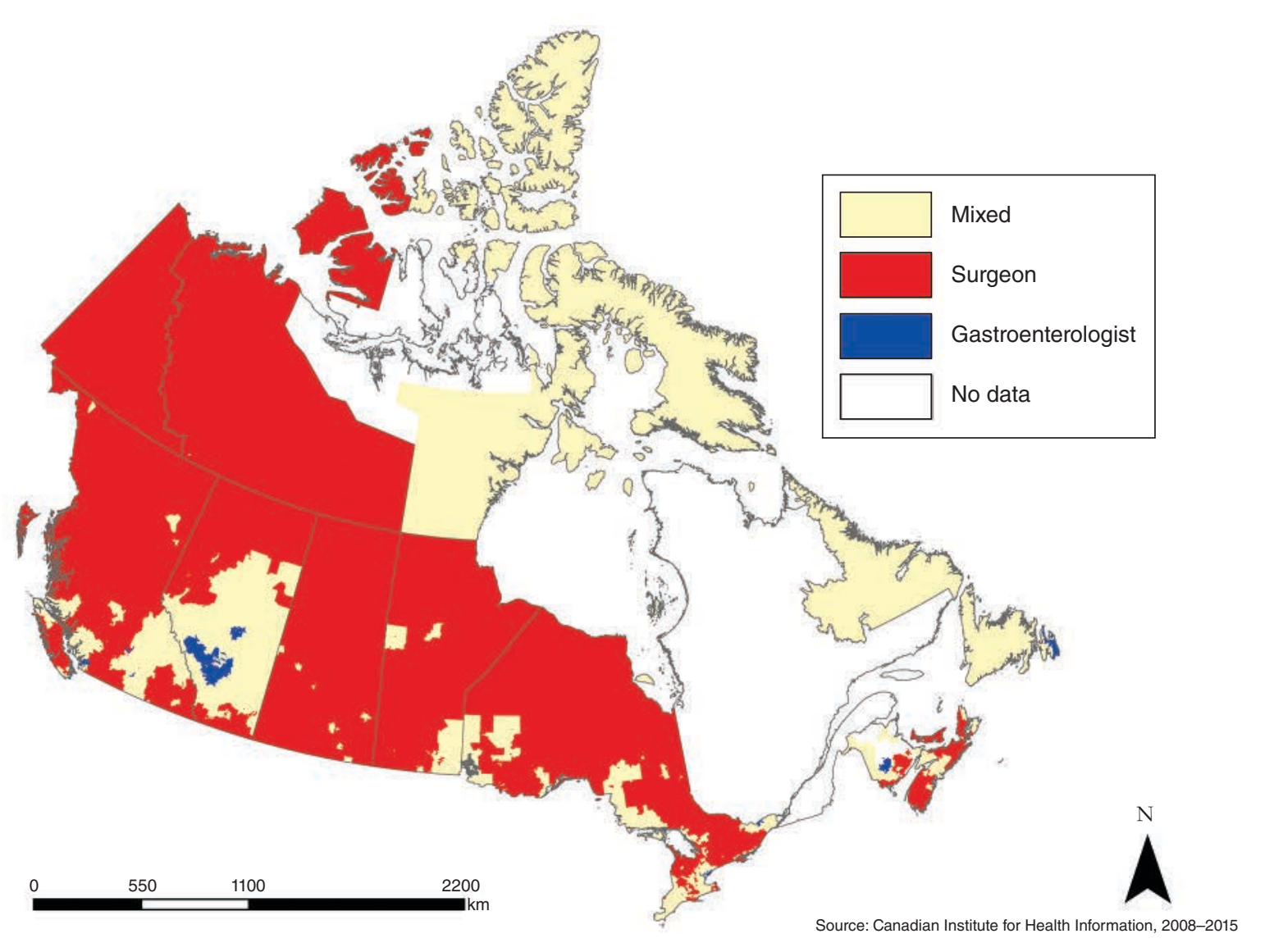

Figure 1: Neighbourhood clustering of screening colonoscopy providers in Canada, April 2008 to March 2015. 
Table 2: Neighbourhood characteristics by screening colonoscopy cluster status

\begin{tabular}{|c|c|c|c|c|c|}
\hline Characteristic & $\begin{array}{c}\text { Gastroenterologist } \\
\text { neighbourhood } \\
n=270\end{array}$ & $\begin{array}{c}\text { Mixed } \\
\text { neighbourhood } \\
n=627\end{array}$ & $\begin{array}{c}\text { Surgeon } \\
\text { neighbourhood } \\
n=217\end{array}$ & $\begin{array}{c}\text { Total } \\
n=1114\end{array}$ & $p$ value \\
\hline $\begin{array}{l}\text { Total no. of colonoscopy } \\
\text { procedures }\end{array}$ & 148253 & 350970 & 158890 & 658113 & \\
\hline $\begin{array}{l}\text { No. }(\%) \text { of colonoscopy } \\
\text { procedures performed by } \\
\text { surgeons }\end{array}$ & 33643 (22.7) & 187604 (53.5) & $131918(83.0)$ & 353165 (53.7) & $<0.001$ \\
\hline Rural & $2(0.7)$ & $52(8.3)$ & 75 (34.6) & $129(11.6)$ & $<0.001$ \\
\hline \multicolumn{6}{|l|}{$\begin{array}{l}\text { Socioeconomic quartile; } \\
\text { no. (\%) of neighbourhoods }\end{array}$} \\
\hline 1 & 58 (21.5) & $153(24.4)$ & $64(24.5)$ & $275(24.7)$ & $<0.001$ \\
\hline 2 & $42(15.6)$ & $153(24.4)$ & $84(38.7)$ & $279(25.0)$ & \\
\hline 3 & $61(22.6)$ & $175(27.9)$ & $45(20.7)$ & $281(25.2)$ & \\
\hline 4 & $109(40.4)$ & 146 (23.3) & 24 (11.1) & $279(25.0)$ & \\
\hline $\begin{array}{l}\text { Distance to health care } \\
\text { facility, mean } \pm S D ; k m\end{array}$ & $17.74 \pm 38.2$ & $36.75 \pm 122.5$ & $59.44 \pm 152.0$ & $36.56 \pm 116.0$ & $<0.001$ \\
\hline
\end{tabular}

colonoscopy care provided by gastroenterologists, and 217 $(19.5 \%)$ were within a cluster that had significantly higher rates of care provided by surgeons; the remainder were in mixed clusters. In gastroenterologist clusters, surgeons performed $22.7 \%$ of colonoscopy procedures, whereas in mixed clusters and surgeon clusters, they performed $53.5 \%$ and $83.0 \%$ of procedures, respectively. Only $2(0.7 \%)$ of the gastroenterologist cluster neighbourhoods were rural areas, compared to $75(34.6 \%)$ of the surgeon cluster neighbourhoods. In addition, $63.0 \%$ of gastroenterologist cluster neighbourhoods were in the 2 highest categories of economic status, compared to $31.8 \%$ of surgeon cluster neighbourhoods. Surgeon clusters were nearly $42 \mathrm{~km}$ farther from the colonoscopy facility than were gastroenterologist clusters $(59.4 \mathrm{~km} \mathrm{v}$. $17.7 \mathrm{~km}$ ). This clearly shows the rural predominance of surgeon clusters, whereas major urban areas tended to be served by gastroenterologists; in suburban areas and smaller cities, care delivery was generally mixed between surgeons and gastroenterologists.

Compared to a mixed neighbourhood cluster, a rural neighbourhood was 0.12 (95\% CI 0.01-0.35) times less likely to be in a gastroenterologist cluster and 5.38 (95\% CI 3.488.01) times more likely to be in a surgeon cluster (Table 3 ). A neighbourhood in the highest socioeconomic quintile was 1.74 (95\% CI 1.14-2.56) times more likely to be in a gastroenterologist cluster than in a mixed cluster and 0.60 (95\% CI $0.33-1.00)$ times less likely to be in a surgeon cluster. Distance was significant only for gastroenterologist clustering: for every $50 \mathrm{~km}$ farther from the colonoscopy facility that a neighbourhood was, the relative risk of being a gastroenterology cluster neighbourhood compared to a mixed cluster neighbourhood was 0.76 times lower (95\% CI 0.58-0.93).

A rural neighbourhood was 98.95 (95\% CI 1.3-427.2) times more likely to be in a surgeon cluster than in a gastro- enterologist cluster (Table 4). A neighbourhood in the highest socioeconomic quintile was 0.35 (95\% CI 0.18-0.61) times less likely to be in a surgeon cluster than in a gastroenterologist cluster. Last, for each $50 \mathrm{~km}$ farther from the colonoscopy facility that a neighbourhood was, it was 1.37 (95\% CI 1.101.77) times more likely to be in a surgeon cluster than in a gastroenterologist cluster.

\begin{tabular}{|lc|}
$\begin{array}{l}\text { Table 3: Multinomial regression results showing the effect of } \\
\text { neighbourhood variables on the relative risk of being a } \\
\text { specialist cluster versus a mixed cluster }\end{array}$ \\
\hline Variable & RR $(95 \% \mathrm{Cl})$ \\
\hline \multicolumn{2}{|l|}{ Gastroenterology cluster v. mixed cluster } \\
\hline Rural & $0.12(0.01-0.35)$ \\
\hline Socioeconomic quartile & Reference \\
\hline 1 & $0.68(0.42-1.05)$ \\
\hline 2 & $0.85(0.55-1.28)$ \\
\hline 3 & $1.74(1.14-2.56)$ \\
\hline 4 & $0.76(0.58-0.93)$ \\
\hline Distance, every $50 \mathrm{~km}$ & \\
\hline Surgical cluster v. mixed cluster & $5.38(3.48-8.01)$ \\
\hline Rural & \\
\hline Socioeconomic quartile & Reference \\
\hline 1 & $1.57(1.00-2.38)$ \\
\hline 2 & $0.78(0.47-1.21)$ \\
\hline 3 & $0.60(0.33-1.00)$ \\
\hline 4 & $1.02(0.96-1.08)$ \\
\hline Distance, every $50 \mathrm{~km}$ & \\
\hline Note: Cl = confidence interval, RR = relative risk. & \\
\hline
\end{tabular}




\begin{tabular}{|lc|}
\hline $\begin{array}{l}\text { Table 4: Multinomial regression results showing the effect of } \\
\text { neighbourhood variables on the relative risk of being a } \\
\text { surgeon cluster versus a gastroenterologist cluster }\end{array}$ \\
\hline Variable & RR $(95 \% \mathrm{Cl})$ \\
\hline Rural & $98.95(15.3-427.2)$ \\
\hline Socioeconomic quartile & Reference \\
\hline 1 & $2.39(1.32-3.99)$ \\
\hline 2 & $0.94(0.51-1.57)$ \\
\hline 3 & $0.35(0.18-0.61)$ \\
\hline 4 & $1.37(1.10-1.77)$ \\
\hline Distance, every 50 km & \\
\hline Note: $\mathrm{Cl}=$ confidence interval, RR $=$ relative risk. \\
\hline
\end{tabular}

\section{Interpretation}

We identified significant patterns in the geographic variation in the delivery of screening colonoscopy in Canada that were consistent across provinces. Overall, there was a clear ruralurban divide between surgeon- and gastroenterologistdelivered care. Surgeons performed $53.7 \%$ of all screening colonoscopy procedures and $73 \%$ of procedures in rural areas. Accordingly, rural neighbourhoods were nearly 100 times more likely to be in a surgeon cluster than a gastroenterology cluster and more than 5 times more likely to be in a surgeon cluster than a mixed cluster. In nonrural areas, surgeons provided $48.7 \%$ of the overall screening colonoscopy care, although this was spread around suburban areas and smaller cities, whereas gastroenterologist care was clustered within major cities such as Toronto, Vancouver, Edmonton, Calgary and Ottawa. This division of the delivery of care was also manifested in the fact that gastroenterologists tended to treat patients of the highest socioeconomic status as well as those who had to travel shorter distances to the health care facility.

Our results are consistent with the finding of Baxter and colleagues $^{28}$ that surgeons performed $53 \%$ of colonoscopy procedures in Ontario. Schultz and colleagues ${ }^{29}$ also found that gastroenterologists and surgeons performed almost the same total number of procedures, although gastroenterologists tended to perform more procedures per physician. Variations in provider distribution between urban and rural areas have also been identified. Hilsden and colleagues ${ }^{15}$ reported that gastroenterologists provided colonoscopy care primarily in large urban areas, whereas surgeons tended to dominate provision of care in smaller urban and rural areas in Canada. However, they could look only at total numbers and were not able to determine whether significant clustering exists. Importantly, a recent systematic review identified a notable lack of studies assessing who provides colonoscopy care in rural areas. ${ }^{16}$ Lower rates of colorectal cancer screening in rural $\operatorname{areas}^{17,18}$ suggest a need for increased provision of colonoscopy care in these regions.

There is evidence that colonoscopy procedures performed by surgeons have similar morbidity and mortality rates as those performed by gastroenterologists..$^{14,30,31}$ In a study of Ontario residents, Rabeneck and colleagues ${ }^{12}$ found that patients who underwent colonoscopy performed by a nongastroenterologist were at significantly increased risk for later development of colorectal cancer. In addition, Ko and colleagues ${ }^{7}$ reported that gastroenterologists were significantly more likely than other specialists to detect and remove polyps during outpatient colonoscopy. However, Kozbial and colleagues ${ }^{13}$ found no significant differences in the rate of polyp or carcinoma detection between general surgeons and internists. However, Baxter and colleagues ${ }^{28}$ did not find a significant association between endoscopist volume and important outcomes such as later development of colorectal cancer.

Our findings clearly show the importance of both gastroenterologists and surgeons in delivering colonoscopy care in Canada. In most neighbourhoods in Canada, the delivery of care is split evenly between the specialties. In addition, their roles seem complementary, as they allow each to provide colonoscopy care in areas where the other would not be able to. Specifically, in rural areas, surgeons fill the gaps in care owing to their ubiquity and ability to supplement their endoscopy practice with a surgical practice. In high-density urban areas, gastroenterologists can fill gaps in coverage where surgeons would likely not be able to meet demand. Recognizing this phenomenon may be a key for provincial health care systems to ensure access to colonoscopy for all patients. ${ }^{32,33}$ This finding also emphasizes the need for endoscopy training for both specialties during residency. This is a specific highlight for surgical programs, in which endoscopy accounts for only part of procedure volume. This training and credentialing during residency is even more important for surgeons planning to practise in rural areas.

The observed division of care also helps to contextualize findings related to practitioner volumes, as it may not be possible for rural surgeons to have high-volume endoscopy practices. Therefore, in an effort to provide access to colonoscopy care, it may be necessary to recognize this fact when creating credentialing guidelines with regard to yearly endoscopy volumes. Guidelines based on the practice of high-volume urban practitioners may have the effect of limiting access to colonoscopy care for patients. Therefore, ensuring access to quality colonoscopy care in rural areas will be an ongoing challenge for the health care system.

\section{Limitations}

This study has several limitations. It covered only colonoscopy procedures that were done in publicly funded health care facilities. The proportion of procedures performed in private endoscopy centres across Canada is largely unknown. ${ }^{34}$ Previous studies showed that, between 1993 and 2005, 84.4\% of colonoscopy procedures performed in Ontario were done in hospitals, $11.4 \%$ were performed in nonhospital settings, and $4.1 \%$ were not classifiable. ${ }^{35}$ Considering that most private endoscopy centres are in urban centres and are run by highvolume endoscopists, it is unlikely that including them would have changed the overall message of this study. In addition, we did not cover all colonoscopy care but, rather, focused on 
screening. The purpose of including only screening colonoscopy was to encompass an overlapping area of practice for surgeons and gastroenterologists, as many other indications for colonoscopy would not overlap as evenly. There is a lack of data on potential provider-level confounders such as years in practice, and this may have influenced the validity of our findings. Last, the authors of the study who are practising physicians are all urban general surgeons and provide colonoscopy care to the community.

\section{Conclusion}

This study clearly shows the division in delivery of screening colonoscopy between rural and urban areas. In rural areas, surgeons were the predominant specialty providing colonoscopy care, whereas gastroenterologists accounted for a larger burden of care in high-density urban areas. This finding underscores the importance of both specialties in achieving access to colonoscopy care for all Canadians. It also highlights the importance of endoscopy in surgical training, especially for those not planning to practise in urban areas. Future research should focus on how this spatial pattern of practice affects outcomes.

\section{References}

1. Arnold M, Sierra MS, Laversanne M, et al. Global patterns and trends in colorectal cancer incidence and mortality. Gut 2017;66:683-91.

2. Muto T, Bussey HJ, Morson BC. The evolution of cancer of the colon and rectum. Cancer 1975;36:2251-70.

3. Telford JJ. Canadian guidelines for colorectal cancer screening. Can 7 Gastroenterol 2011;25:479-81.

4. Baxter NN, Goldwasser MA, Paszat LF, et al. Association of colonoscopy and death from colorectal cancer. Ann Intern Med 2009;150:1-8.

5. Winawer SJ, Zauber AG, Ho MN, et al. Prevention of colorectal cancer by colonoscopic polypectomy. N Engl 7 Med 1993;329:1977-81.

6. Elmunzer BJ, Singal AG, Sussman JB, et al. Comparing the effectiveness of competing tests for reducing colorectal cancer mortality: a network meta-analysis. Gastrointest Endosc 2015;81:700-9.e3.

7. Ko CW, Dominitz JA, Green P, et al. Specialty differences in polyp detection, removal, and biopsy during colonoscopy. Am 7 Med 2010;123:528-35.

8. Provenzale D, Ofman J, Gralnek I, et al. Gastroenterologist specialist care and care provided by generalists - an evaluation of effectiveness and efficiency. Am 7 Gastroenterol 2003;98:21-8.

9. Ollington KF, Brelian D, Morgan J, et al. Comparison of adenoma detection rates between gastroenterologists and colorectal surgeons. Am Surg 2012;78:269-70.

10. Baxter NN, Warren JL, Barrett MJ, et al. Association between colonoscopy and colorectal cancer mortality in a US cohort according to site of cancer and colonoscopist specialty. 7 Clin Oncol 2012;30:2664-9.

11. Bielawska B, Day AG, Lieberman DA, et al. Risk factors for early colonoscopic perforation include non-gastroenterologist endoscopists: a multivariable analysis. Clin Gastroenterol Hepatol 2014;12:85-92.

12. Rabeneck L, Paszat LF, Saskin R. Endoscopist specialty is associated with incident colorectal cancer after a negative colonoscopy. Clin Gastroenterol Hepatol 2010;8:275-9.

13. Kozbial K, Reinhart K, Heinze G, et al. High quality of screening colonoscopy in Austria is not dependent on endoscopist specialty or setting. Endoscopy 2015; 47:207-16.

14. Mehran A, Jaffe P, Efron J, et al. Colonoscopy: Why are general surgeons being excluded? Surg Endosc 2003;17:1971-3.

15. Hilsden RJ, Tepper J, Moayyedi P, et al. Who provides gastrointestinal endoscopy in Canada? Can 7 Gastroenterol 2007;21:843-6.

16. Evans DV, Cole AM, Norris TE. Colonoscopy in rural communities: a systematic review of the frequency and quality. Rural Remote Health 2015;15:3057.
17. Cole AM, Jackson JE, Doescher M. Urban-rural disparities in colorectal cancer screening: cross-sectional analysis of 1998-2005 data from the Centers for Disease Control's Behavioral Risk Factor Surveillance Study. Cancer Med 2012;1:350-6.

18. Ojinnaka CO, Choi Y, Kum HC, et al. Predictors of colorectal cancer screening: Does rurality play a role? 7 Rural Health 2015;31:254-68.

19. Canadian Task Force on Preventive Health Care; Bacchus CM, Dunfield L, Gorber SC, et al. Recommendations on screening for colorectal cancer in primary care. CMAZ 2016;188:340-8.

20. Lee DS, Stitt A, Wang X, et al. Administrative hospitalization database validation of cardiac procedure codes. Med Care 2013;51:e22-6.

21. Joseph KS, Fahey J; Canadian Perinatal Surveillance System. Validation of perinatal data in the Discharge Abstract Database of the Canadian Institute for Health Information. Cbronic Dis Can 2009;29:96-100.

22. Data quality documentation, Discharge Abstract Database, 2008-2009: executive summary. Ottawa: Canadian Institute for Health Information; 2010 [revised Feb. 2011].

23. Ko CW, Dominitz JA, Neradilek M, et al. Determination of colonoscopy indication from administrative claims data. Med Care 2014;52:e21-9.

24. Fisher DA, Grubber JM, Castor JM, et al. Ascertainment of colonoscopy indication using administrative data. Dig Dis Sci 2010;55:1721-5.

25. Health region boundary files. Ottawa: Statistics Canada [modified 2015 Nov. 27]. Available: https://www.statcan.gc.ca/pub/82-402-x/2013002/reg-eng.htm (accessed 2017 May 10).

26. Table 105-0501 - Health indicator profile, annual estimates, by age group and sex, Canada, provinces, territories, health regions (2013 boundaries) and peer groups. CANSIM [database]. Ottawa: Statistics Canada [modified 2016 Apr. 21]. Available: www5.statcan.gc.ca/cansim/a26?lang=eng\&retrLang=eng\&id= $1050501 \& \&$ pattern $=\&$ stByVal $=1 \& \mathrm{p} 1=1 \& \mathrm{p} 2=-1 \&$ tabMode $=$ data Table $\& \operatorname{csid}=$ (accessed 2017 May 10).

27. Table 111-0009 - Characteristics of families, summary census family income table. CANSIM [database]. Ottawa: Statistics Canada [modified 2017 July 11]. Available: www5.statcan.gc.ca/cansim/a26?lang=eng\&id=1110009 (accessed 2017 May 10).

28. Baxter NN, Sutradhar R, Forbes SS, et al. Analysis of administrative data finds endoscopist quality measures associated with postcolonoscopy colorectal cancer. Gastroenterology 2011;140:65-72.

29. Schultz SE, Vinden C, Rabeneck L. Colonoscopy and flexible sigmoidoscopy practice patterns in Ontario: a population-based study. Can $\mathcal{F}$ Gastroenterol 2007;21:431-4.

30. Wexner SD, Garbus JE, Singh JJ; SAGES Colonoscopy Study Outcomes Group. A prospective analysis of 13,580 colonoscopies. Reevaluation of credentialing guidelines. Surg Endosc 2001;15:251-61.

31. Wexner SD, Forde KA, Sellers G, et al. How well can surgeons perform colonoscopy? Surg Endosc 1998;12:1410-4.

32. Sheffield KM, Han Y, Kuo YF, et al. Potentially inappropriate screening colonoscopy in Medicare patients. 7AMA Intern Med 2013;173:542-50.

33. Johnson MR, Grubber J, Grambow SC, et al. Physician non-adherence to colonoscopy interval guidelines in the Veterans Affairs healthcare system. Gastroenterology 2015;149:938-51.

34. Alharbi O, Rabeneck L, Paszat L, et al. Factors associated with colonoscopy performed in nonhospital settings. Can 7 Gastroenterol 2010;24:419-24.

35. Ivers $\mathrm{N}$, Schwandt $\mathrm{M}$, Hum $\mathrm{S}$, et al. A comparison of hospital and nonhospital colonoscopy: wait times, fees and guideline adherence to follow-up interval. Can 7 Gastroenterol 2011;25:78-82.

Affiliations: Department of Surgery (Doumouras, Cadeddu, M. Anvari, Hong), McMaster University; Division of General Surgery (Doumouras, M. Anvari, Cadeddu, S. Anvari, Hong), St. Joseph's Healthcare, Hamilton, Ont.

Contributors: Aristithes Doumouras, Sama Anvari and Dennis Hong designed the study, acquired and analyzed the data and drafted the manuscript. Margherita Cadeddu, Mehran Anvari and Dennis Hong critically revised the manuscript for important intellectual content. All of the authors made substantial contributions to the study conception and the interpretation of the data, gave final approval of the version to be published and agreed to be accountable for all aspects of the work.

Supplemental information: For reviewer comments and the original submission of this manuscript, please see www.cmajopen.ca/content/6/1/ E126/suppl/DC1. 